\title{
ОБРАБАТЫВАЮЩАЯ ПРОМЫШЛЕННОСТЬ: ДОБАВЛЕННАЯ СТОИМОСТЬ В ГЛОБАЛЬНОМ МИРЕ
}

\author{
(c) 2019 Уманский Анатолий Михайлович \\ соискатель кафедры экономики и управления предприятиями и производственными комплексами \\ Санкт-Петербургский государственный экономический университет, Россия, Санкт-Петербург \\ E-mail:uam_777@mail.ru
}

В настоящей публикации автором предложен анализ тенденций экономической трансформации обрабатывающей промышленности. Представлены предпосылки и ключевые факторы конкурентоспособности. На основе представленного количественного анализа динамики и структуры добавленной стоимости сформулирована глобальная, пространственная перспектива развития обрабатывающей промышленности. Работа выполнена в рамках плана исследований научной школы СПбГЭУ «Экономика, организация и управление предприятиями, отраслями, комплексами; управление инновациями; экономика оборонно-промышленного комплекса» (руководитель - профессор Карлик А.Е.).

Ключевые слова: экономика, промышленность, добавленная стоимость.

Трансформация институциональной позиции обрабатывающей промышленности в мировой экономике осознана и сформулирована в научных публикациях. «...Экономика промышленности превращается из производственной в более интеллектуальную модель, основанную на производительности...» Stahel W.R. [1]. Вопросы предпосылок и драйверов конкурентоспособности исследованы в профильных публикациях российских и зарубежных авторитетных ученых: Клейнер Г.Б. [2], Карлик А.Е. [3], Ивантер В.В. [4], Фомина Н.Е. [5], Алексеев А.А. [6], Gereffi G. [7], Davis J. [8], Miltenburg J. [9], Stahel W. R. [1], AmoakoGyampah K. [10], Garetti M. [11], Sutherland J.W. [12], Paiva E.L. [13] и др. Индикативные модели формирования конкурентоспособности обрабатывающей промышленности разрабатываются исследовательскими институтами и консалтинговыми группами: Институт экономики РАН, The Royal Institute of International Affairs [14], Deloitte [15] и другие.

Предпосылками институциональной трансформации в настоящее время определяют 4 фактора:

1. 4-я промышленная революция, изменяющая не только производственный процесс, но и принципы взаимодействия с поставщиками и потребителями на основе цифровых технологий (интернет-вещи, чипирование, интернет след и др.). Фактически пересматривается экономика промышленности (Карлик А.Е. [3], Фомина Н.Е. [5]) в части баланса производительных сил и от- ношений;

2. Возникновение новых отраслей обрабатывающей промышленности, обусловленное инновационными факторами (Алексеев А.А. [16]). Демонстрацией этого является изменение структуры мирового импорта (табл. 1). Углубляется тенденция роста товарооборота высокотехнологичного сектора и, связанных с ним в цепочке добавленной стоимости, отраслей и комплексов. При этом низко- и средне- технологичный сектора не демонстрируют роста, пропорционального динамике мировой экономики;

3. Доля промышленности в мировом ВВП сокращается (рис. 1), что обусловлено смещением фокуса инвестирования в информационные технологии и сервисы (Ивантер В.В. [4]). Изменяется глобальная маркетинговая парадигма доля информационных продуктов и сервисов в структуре потребления выросла в 7 раз только за последние 10 лет [17];

4. Возвращение промышленности в развитые страны. Концепция новой индустриализации развитых стран выражается в отказе от локализации производства за рубежом, в первую очередь стран Азиатско-Тихоокеанского региона (Davis J. [8]). Во многом данная предпосылка влияет и на географическую структуру импорта, изменяет глобальные цепочки добавленной стоимости (Gereffi G. [7]).

Выделенные предпосылки предопределяют и новую структуру факторов конкурентоспособ- 
Таблица 1. Мировой импорт и его средние темпы (2010-2018) продуктов, млрд. USD. Выборочная статистика, интерпретированная автором данным UNCTAD *

\begin{tabular}{|l|c|c|c|}
\hline Продукты & 2010 & 2018 & $\Delta 2010-18$ \\
\hline Всего всех товаров & 15367,9 & 19714,8 & $28 \%$ \\
\hline Синтетическая резина & 22,6 & 28,7 & $27 \%$ \\
\hline Медь & 125,5 & 138,3 & $10 \%$ \\
\hline Никель & 22,8 & 22,0 & $-3 \%$ \\
\hline Алюминий & 103,6 & 141,8 & $37 \%$ \\
\hline Цинк & 12,1 & 19,6 & $62 \%$ \\
\hline Лекарственные и фарм. препараты & 137,1 & 250,6 & $83 \%$ \\
\hline Медикаменты & 337,0 & 415,1 & $23 \%$ \\
\hline Полиграфическое оборудование & 15,1 & 12,5 & $-17 \%$ \\
\hline Машины пищевого производства & 11,8 & 16,6 & $41 \%$ \\
\hline Металлообрабатывающее оборудование & 19,5 & 22,4 & $15 \%$ \\
\hline Машины автоматической обработки данных & 328,8 & 394,0 & $20 \%$ \\
\hline Телевизионные приемники & 102,6 & 92,4 & $-10 \%$ \\
\hline Приемники радиовещания & 17,6 & 13,0 & $-27 \%$ \\
\hline Телекоммуникационное оборудование & 494,4 & 611,1 & $24 \%$ \\
\hline Автомобили для перевозки людей & 557,1 & 788,9 & $42 \%$ \\
\hline Мотоциклы и велосипеды & 39,2 & 56,7 & $45 \%$ \\
\hline Авиация и сопутствующее оборудование & 158,7 & 231,6 & $46 \%$ \\
\hline Корабли, лодки и плавучие сооружения & 95,1 & 80,8 & $-15 \%$ \\
\hline Оптические приборы и аппаратура & 81,4 & 74,3 & $-9 \%$ \\
\hline Ювелирные изделия & 68,2 & 100,1 & $47 \%$ \\
\hline
\end{tabular}

Режим доступа: https://unctad.org 22.10.2019.

ности обрабатывающей промышленности. Так исследовательский институт «The Royal Institute of International Affairs» актуальными драйверами конкурентоспособности видит следующие (интерпретировано автором по [14]):

- «Индекс исследований» - компилятивный взгляд на роль научно-исследовательских и опытно-конструкторских работ, относительную величину затрат в товарообороте, широту кооперации с рынком старт-апов и индекс конверсии разработок в серийное производство инновационных продуктов. В целом измеряется как наукоемкость предприятия - доля затрат на НИОКР в товарообороте;

- «Конкурентоспособность затрат» как совокупность решений и подходов к управлению себестоимостью в условиях неэластичности даже инновационных продуктов обрабатывающей промышленности. Если ранее инновационное предприятие могло использовать «стратегию снятия сливок», то есть не было значимо ограничено расходами НИОКР и производства. То актуальном периоде себестоимость «жестко» предо- пределена рыночной ценой продукта и нормой доходности предприятий и комплексов;

- «Производительность» - традиционный индикатор и/или элемент стратегического КРI предприятий обрабатывающей промышленности, характеризующий эффективность управления балансом производства и привлекаемыми человеческими ресурсами. Данный показатель конкурентоспособности входит во все микро-, мезо- и макро- уровневые стратегии обрабатывающей промышленности практически всех стран;

- «Сеть поставщиков» понимается как эффективность управления цепями поставок в условиях критического сокращения длительности жизненного цикла продукции обрабатывающей промышленности, перманентности обновления номенклатуры и ассортимента в силу инновационности спроса. В этих условиях конкурентоспособность обеспечивается устойчивостью взаимодействия с поставщиками, взаимосвязи программ инновационного развития, в экономическом смысле - в поиске эффектов сниже- 
ния транзакционных расходов предприятий обрабатывающей промышленности.

Концептуально схоже, но с иным видением приоритетов рассматриваются факторы конкурентоспособности обрабатывающей промышленности исследовательской группой Deloitte (отчет «Global Manufacturing Competitiveness Index» [15]):

- «Таланты» - инвестирование в человеческий капитал, развитие научно-исследовательского и производственного персонала, поддержка инновационных инициатив и предпринимательства сотрудников является ключевой задачей предприятий обрабатывающей промышленности. Акцентирование на приоритете человеческого в структуре интеллектуального капитала является перспективной стратегий формирования конкурентоспособности обрабатывающей промышленности;

- «Передовые технологии» - реализуется как стратегия перманентного расширенного воспроизводства основных фондов предприятий. Экономическая эффективность предопределяется технологическим уровнем оборудования, что реализуется фактором управления себестоимостью и производительностью в основном цикле тиражирования;

- «Эко-системное партнерство». Промышленные сети организуются на основе новой топологии. Если ранее они организовывались по кластерному принципу, объединяя участников производственной цепи по логистическому принципу, то современная модель выстраивается во взаимосвязи субъектов со связанными принципами и ориентирами инновационного, инвестиционного развития. То есть, наблюдается переход от вертикального к линейному партнерству в промышленных сетях. Взаимосвязанная группа понимается как «эко-системное» партнерство;

- «Ресурсная сбалансированность» как фактор формулируется в контексте доминирующей концепции «устойчивого развития» (Джексон Т. [18]). Макро- и мезо- позиция обрабатывающей промышленности в контексте потребления и распределения ресурсов определяется как взаимосвязанная в «эко- системном партнерстве». Стратегическая позиция производства и потребления обрабатывающей промышленности формулируется в рамках концепции «зеленой экономики» (Kharkongor N.W. [19]);

- «Государственно-частное партнерство» не впервые формулируется в научной и публицистической литературе как фактор экономического развития, но в структуре топ-5 драйверов конкурентоспособности обрабатывающей промышленности такая позиция нова. Это обусловлено, во-первых, сложившейся тенденцией отказа от локализации производства развитыми странами, в рамках которой государственная «промышленная политика» становится реальным инструментом управления производственными силами и отношениями [12]. Во-вторых, формирования про- активной позиции ряда стран в части государственного инвестирования в перспективные, относящиеся к VI технологическому укладу (Малинецкий Г.Г. [20]), производства и научно-исследовательские направления.

Совокупность выделенных предпосылок и структуры факторов конкурентоспособности обрабатывающей промышленности позволяют видеть картину текущей экономической трансформации реального сектора экономики. Глобальный контекст которой вполне объективно отражается динамикой и структурой добавленной стоимости, в отличии от других индикаторов (товарооборот, инвестиции и др.) выражающей именно экономическую стратегию и эффективность развития производительных сил изучаемого сектора. Данный индикатор является определяющим и с позиции [21] развития обрабатывающей промышленности в разрезе экономики стран. Первично автор проанализировал динамику добавленной стоимости обрабатывающей промышленности в структуре ВВП, тенденциозно выделив (по базам данных Мирового Банка) ряд стран относительно среднемировой, рис. 1. На фоне глобального тренда снижения доли обрабатывающей промышленности в экономике стран (по причине роста инвестиционной привлекательности сектора ИТ), можно выделить 3 группы (А, В, С рис. 1) стран с различной экономической стратегией в отношении сектора. Нужно отметить, что данные стратегии не связаны с уровнем развития экономик, например предлагаемой Мировым Банком (табл. 2), не предопределены таковыми. Группа А, в которой наиболее выражена стратегия у Китая, доля обрабатывающей промышленности в формировании ВВП традиционно велика (28-35\%). Страны группы А, традиционные доноры технологий, локализующие производства, формируют стратегию сохранения (на фоне возвращения промышленности в развитые страны) уровня 


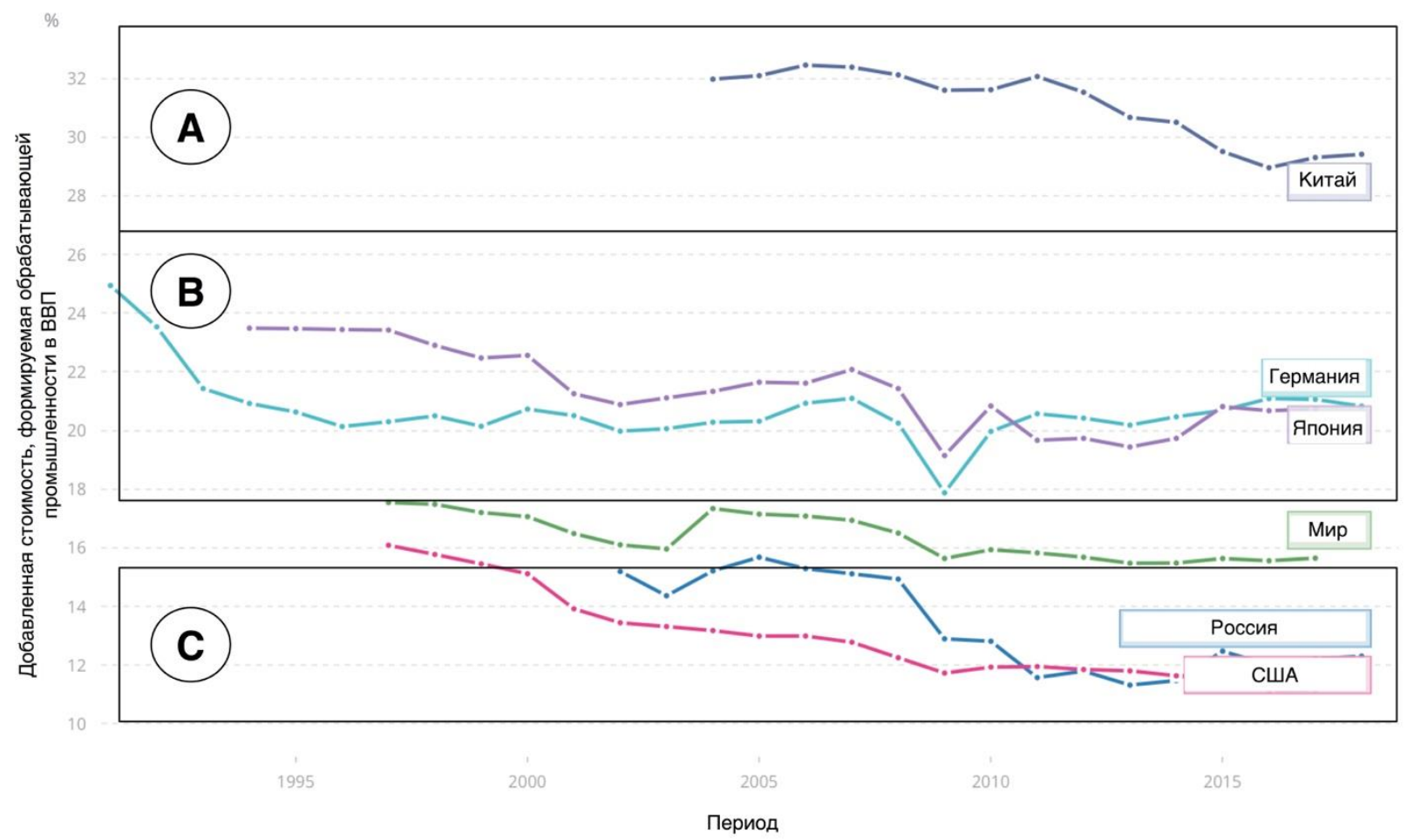

Puc. 1. Динамика добавленной стоимости обрабатывающей промышленности в структуре ВВП (претенциозная выборка).

Интерпретировано по базам данных Мирового Банка, 2019. Режим доступа: https://data.worldbank.org 28.10.2019.

обрабатывающей промышленности в ВВП за счет переориентации предложения на внутренние и стран БРИКС рынки. В перспективе группа А будет реализовывать стратегию экономического роста за счет развития сектора обрабатывающей промышленности. Такой вывод вполне очевиден и подтверждается динамикой валового объема добавленной стоимости для данной группы стран, табл. 2. Группу В составляют сложившиеся лидеры научно-технического и производственного развития - страны ЕС и Япония, традиционное ядро мировой обрабатывающей промышленности.

Доля в ВВП в данной группе выше среднемировой - 18-27\%. Незначительное снижение уровня индикатора за последние 10 лет как раз и обусловлено в этой группе ростом сектора инфокоммуникационных технологий. В частности, драйвер 4-й промышленной революции именно в этой группе проявляется наиболее объективно. Изменяется экономика производства в части структуры себестоимости - наблюдается значимый рост расходов на инфокоммуникационные технологии и сервисы [17]. И третья группа (C), с наиболее выраженной стратегией - США и Россия, объединяет страны с сильным топливно-энергетическим сектором, сохраняющим верхние строчки в рейтинге инвестиционной привлекательности глобальных инвесторов. У них доля обрабатывающей промышленности в ВВП находится в диапазоне $10-16 \%$, уступая секторам ТЭК, ИТ и услуг. Представленные 3 группы выражают различные национальные стратегии с позиции роли и места обрабатывающей промышленности в структуре экономического роста.

В качестве второй черты трансформации глобальной обрабатывающей промышленности автор видит изменение баланса добавленной стоимости, производимой странами с высоким и средним доходом (классификация Мирового Банка), выборочная, тенденциозная динамика которой представлена в табл. 2 и на рис. 2. В 2004 году баланс был представлен доминированием стран с высоким доходом в формировании валовой добавленной стоимости обрабатывающей промышленностью, оставляя странам со средним доходом первичную переработку сырья, изготовление комплектующих и другие циклы с низкой добавленной стоимостью. 
Таблица 2. Выборочная статистика (по базам данных Мирового Банка*) о величине добавленной стоимости (млрд. USD) обрабатывающей промыш-ленности в разрезе стран и группировок.

\begin{tabular}{|l|r|r|r|r|r|r|}
\hline Страны & 2004 & 2010 & 2014 & 2017 & 2017 & $\begin{array}{l}\text { Сp. темп } \\
\text { роста } \\
(2004- \\
17)\end{array}$ \\
\hline Всего (мир) & 7245,1 & 10557,4 & 12698,6 & 13173,9 & $100,0 \%$ & $4,9 \%$ \\
\hline Бразилия & 101,1 & 281,0 & 253,9 & 216,4 & $1,6 \%$ & $7,4 \%$ \\
\hline Европа & 141,2 & 230,8 & 270,9 & 275,6 & $2,1 \%$ & $6,0 \%$ \\
\hline Швейцария & 74,7 & 109,7 & 130,2 & 121,7 & $0,9 \%$ & $4,2 \%$ \\
\hline Китай & 625,2 & 1924,3 & 3184,2 & 3558,4 & $27,0 \%$ & $14,7 \%$ \\
\hline Германия & 571,7 & 682,3 & 797,9 & 777,8 & $5,9 \%$ & $2,9 \%$ \\
\hline $\begin{array}{l}\text { Восточная Азия и } \\
\text { Тихоокеанский } \\
\text { регион }\end{array}$ & 2265,2 & 4117,4 & 5353,9 & 5857,8 & $44,5 \%$ & $7,8 \%$ \\
\hline Франция & & & & & 2,0 \\
\hline Япония & 1027,2 & 1187,5 & 957,0 & 1007,3 & $7,6 \%$ & $0,2 \%$ \\
\hline Северная Америка & 1759,9 & 1956,0 & 2215,6 & 2338,2 & $17,7 \%$ & $2,3 \%$ \\
\hline США & 1609,8 & 1789,0 & 2039,4 & 2173,3 & $16,5 \%$ & $2,4 \%$ \\
\hline Россия & 89,9 & 195,4 & 236,4 & 192,9 & $1,5 \%$ & $8,7 \%$ \\
\hline Группировки & \multicolumn{7}{|c|}{} \\
\hline Высокий доход & 5540,8 & 6449,9 & 6941,5 & 7070,5 & $53,7 \%$ & $2,0 \%$ \\
\hline Средний доход & 1685,5 & 4079,2 & 5720,9 & 6062,8 & $46,0 \%$ & $10,7 \%$ \\
\hline $\begin{array}{l}\text { Низкий уровень } \\
\text { дохода }\end{array}$ & 15,4 & 28,7 & 41,0 & 42,6 & $0,3 \%$ & $8,3 \%$ \\
\hline
\end{tabular}

* Режим доступа: https://data.worldbank.org 28.10.2019.

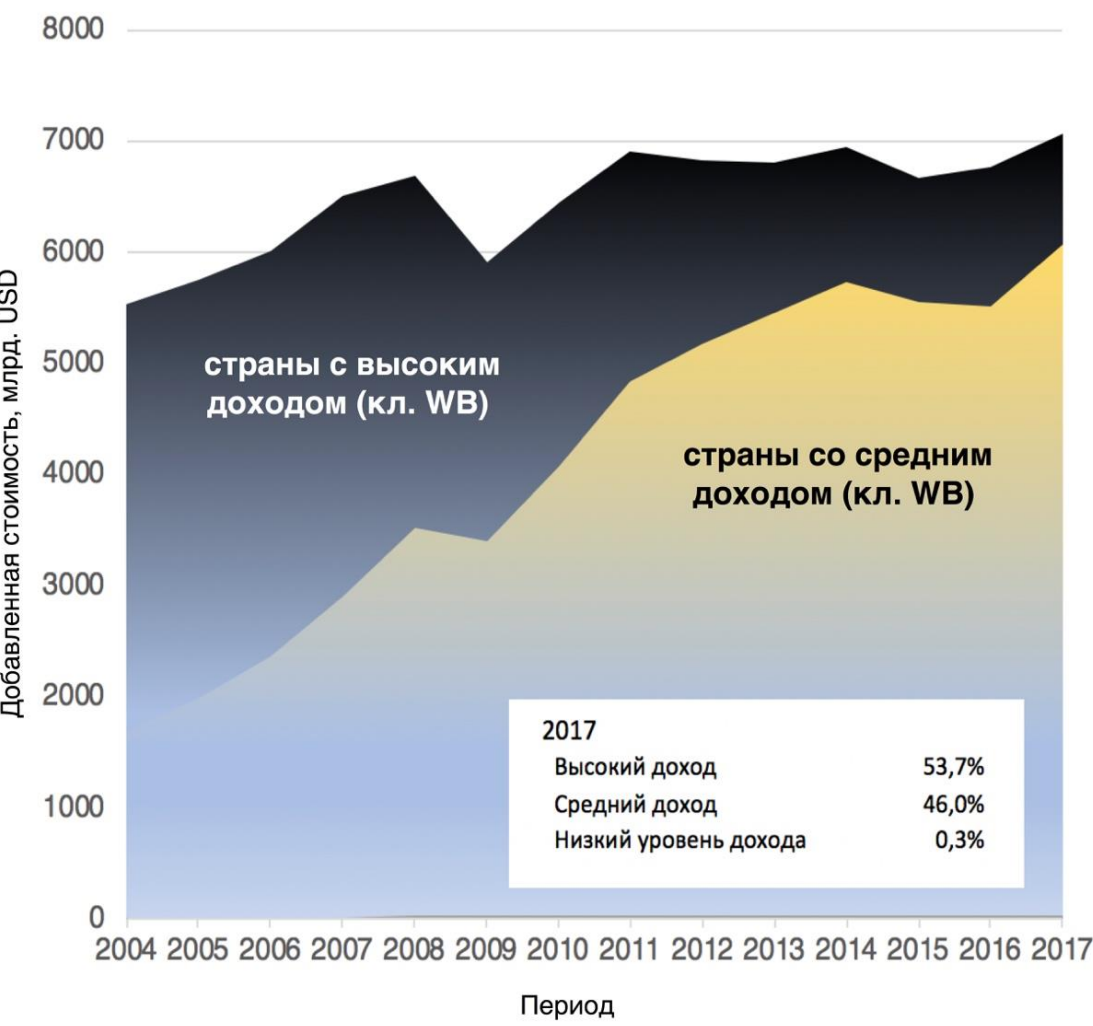

Puc. 2. Объем и динамика валовой добавленной стоимости, сгруппированные по станам с различным уровнем дохода (по базам данных Мирового Банка, табл. 2). 
В современном мире баланс значительно изменился - сложился паритет по валовому объему добавленной стоимости между странами в группах высокого и среднего дохода. Это нивелирует само понятие «промышленно развитых» стран, имевшее институциональное значение в экономической науке начала века. Причина этого в трансформации структуры глобальных цепочек добавленной стоимости (Gereffi G. [7]), причем не законченной к настоящему моменту трансформации с позиции пространственных границ взаимодействия рынков и производителей (Deloitte [15]).

В представленном контексте может быть сформулирован ключевой (практически ориентированный в рамках настоящего исследования) вывод для формирования «промышленной политики» в отношении национальной обрабатывающей промышленности: необходимо не догонять «промышленно развитые» страны по уровню традиционных промышленных индикаторов, а формировать стратегически оптимальную позицию в мировых цепочках добавленной стоимости. Что предопределяет направление дальнейших исследований как научный и практический поиск продуктовых направлений для интеграции национальных производств в сложившиеся и перспективные цепочки добавленной стоимости.

\section{Выводы:}

Представленное в работе авторское исследование предпосылок, ключевых факторов конкурентоспособности, количественных показателей динамики и пространственного распределения объемов добавленной стоимости формализует институциональный экономический профиль обрабатывающей промышленности. В рамках которого автор формулирует следующие научные выводы:

1. Наблюдается трансформация структуры факторов конкурентоспособности, изменяющая баланс производственных сил и отношений в секторе обрабатывающей промышленности. На смену «производственной», приходит «экосистемная» модель, построенная на научнотехнических, инновационных драйверах устойчивости развития;

2. Выделены 3 группы стратегий, дифференцированных с позиции роли обрабатывающей промышленности в структуре факторов национального экономического роста. Максимизация доли добавленной стоимости обрабатывающей промышленностью в ВВП не является аксиоматическим признаком экономического роста в современных условиях. Национальная стратегия в отношении обрабатывающей промышленности должна быть выстроена с учетом перспектив инвестиционного развития других секторов (ИТ и услуги, в первую очередь);

3. В сложившемся мировом балансе добавленной стоимости перспективной видится национальная стратегия не валового и индикативного роста всех показателей обрабатывающей промышленности, а уровня интеграции в глобальные цепочки добавленной стоимости по наиболее перспективным направлениям. В практическом смысле данный вывод согласуется (адресован в развитие) с национальным проектом «Международная кооперация и экспорт» (2019 по 2024 год), требующего дополнения в части разработки научно-методических механизмов выбора отраслей обрабатывающей промышленности, перспективных с позиции глобальной интеграции.

\section{Библиографический список}

1. Stahel, W.R. The Performance Economy. The Performance Economy, 2010.

2. Клейнер Г.Б. Системная модернизация отечественных предприятий: теоретическое обоснование, мотивы, принципы // Экономика региона. - 2017.- Т. 13.- Вып. 1.- С. 13-24.

3. Карлик А. Е., Платонов В.В. Сетевая организация как механизм промышленного развития. Проблемы теории и практики управления. 2016. № 9. С. 92-102.

4. Ивантер В.В., Комков Н.И. Основные положения концепции инновационной индустриализации России. Проблемы прогнозирования. 2012. № 5 (134). С. 3-13.

5. Фомина Н.Е., Маркевич С.В. Глобальный контекст развития промышленности. Вопросы экономики и права. 2013. № 3. С. 14.

6. Алексеев А.А., Хлебников К.В. Структура факторов производства высокотехнологичных предприятий, обеспечивающих устойчивость инновационного развития. Вопросы экономики и права. 2016. № 99. С. 39-44.

7. Gereffi G., Fernandez-Stark K. Global Value Chain Analysis: A Primer. Duke University. North Carolina. USA, 2011. 
8. Davis, J., Edgar, T., Porter, J., Bernaden, J., \& Sarli, M. Smart manufacturing, manufacturing intelligence and demand-dynamic performance. Computers and Chemical Engineering, 2012.

9. Miltenburg, J. Setting manufacturing strategy for a factory-within-a-factory. International Journal of Production Economics, 2008.

10. Amoako-Gyampah, K., \& Acquaah, M. Manufacturing strategy, competitive strategy and firm performance: An empirical study in a developing economy environment. International Journal of Production Economics, 2008.

11. Garetti, M., \& Taisch, M. Sustainable manufacturing: Trends and research challenges. Production Planning and Control, 2012.

12. Sutherland, J.W. etc. The role of manufacturing in affecting the social dimension of sustainability. CIRP Annals Manufacturing Technology, 2016.

13. Paiva, E.L. Manufacturing and marketing integration from a cumulative capabilities perspective. International Journal of Production Economics, 2010.

14. House Report July 2013. GB: The Royal Institute of International Affairs, 2013.

15. Global Manufacturing Competitiveness Index. Deloitte, 2018.

16. Алексеев А.А., Хлебников К.В. Факторы экономической эффективности инновационного предпринимательства в обрабатывающей промышленности. Известия Санкт-Петербургского государственного экономического университета. 2018. № 5 (113). С. 128-136.

17. The World's Industrial Transformation. (Donald Hepburn, Andrew Black, Matteo Ferrazzi, Andrea Goldstein, David Hurst, Steven McGuire and Michael Owen). A Chatham House, 2009.

18. Джексон Т. Процветание без роста. Экономика для планеты с ограниченными ресурсами = Рrosperity without Growth. Economics for a Finite Planet / Пер. с англ._- М.: АСТ-Пресс, 2013. - 304 с.

19. Kharkongor N.W. Green economics: sustainability funding. International Journal of Green Economics 10(2), January 2016.

20. Малинецкий Г.Г. Модернизация - курс на VI технологический уклад // Препринты ИПМ им. М.В. Келдыша.М., 2010.- № 41.- С. 16-19.

21. Добавленная стоимость / А.Е. Косарев // Большая российская энциклопедия: [в 35 т.] / гл. ред. Ю.С. Осипов.М.: Большая российская энциклопедия, 2004-2017. 